Pine, L. \& Howell, A. Jun. (1956). J. gen. Microbiol. 15, 428-445

\title{
Comparison of Physiological and Biochemical Characters of Actinomyces spp. with those of Lactobacillus bifidus
}

\author{
By L. PINE \\ Laboratory of Infectious Diseases, National Institute of Allergy \\ and Infectious Diseases \\ AND A. HOWELL, Jun. \\ National Institute of Dental Research, National Institutes of Health, \\ Public Health Service, U.S. Department of Health, Education \\ and Welfare, Bethesda 14, Maryland, U.S.A.
}

SUMMARY: Evidence is presented that under the conditions described 11 strains of Actinomyces spp., representing strains described as $A$. israelii, $A$. israelii-like or A. naeslundii, require carbon dioxide for anaerobic growth. Some of these strains, under these conditions, are obligate anaerobes to microaerophils, while others appear to be facultative anaerobes. Cultures which are capable of aerobic growth may or may not require carbon dioxide for such growth. Of three strains of Lactobacillus bifidus tested, all required carbon dioxide for anaerobic growth. One avian strain required carbon dioxide to give limited aerobic growth; the remaining strains did not grow significantly under aerobic conditions. Comparisons of several strains of Actinomyces spp. with L. bifidus indicated that of eleven sugars tested, the sugar of choice for growth of Actinomyces spp. was glucose or maltose, whereas lactose or maltose was preferred by strains of $L$. bifidus. All strains of each group of organisms were found to be catalase-negative; none liquefied gelatin; all eleven strains of Actinomyces spp. reduced nitrate to nitrite, but none of the bifid strains possessed this ability; production of acetylmethylcarbinol was variable in both groups. All strains of Actinomyces spp. tested formed L (+) lactic acid, although the results suggested that small amounts of $\mathrm{D}(-)$ lactic acid were also formed. Fermentation analyses indicated that strains of $L$. bifidus and Actinomyces spp. form the same products from glucose and carbon dioxide (lactic, acetic, formic and succinic acids). However, strains of Actinomyces spp. form predominantly lactic acid with small amounts of acetic, formic and succinic acids; whereas the strains of $\boldsymbol{L}$. bifidus form approximately equal amounts of lactic and acetic acids (based on glucose fermented) with trace amounts of succinic and formic acids. Actinomyces strains fermented but 34-59\% of the glucose supplied as compared to the strains of $L$. bifidus which used from 59 to $89 \%$ of the glucose ( $1 \%$ glucose medium).

The relationship of Lactobacillus bifidus to the genus Actinomyces was apparently first noted by Vuillemin (1931). Puntoni (1937) noted certain morphological, biochemical and immunological resemblances between strains of Actinomyces spp. and $L$. bifidus. He concluded that the organisrns were sufficiently similar to be placed in the same genus and species, although he felt a species differentiation might be made. Negroni \& Fischer (1944), from a study of L. bifidus, concluded that this organism should be placed in the genus Cohnistreptothrix (Actinomyces). Frank \& Skinner (1954), on primarily morphological grounds, suggested that $L$. bifidus be placed in the genus Actinomyces as $A$. bifidus. However, each of these studies was somewhat limited in extent. In addition, 
any conclusions regarding the relationship of these organisms to one another have been limited by the lack of information on certain biochemical properties of organisms of the genus Actinomyces. Consequently, it seemed worth while to make comparisons of these two groups of organisms on the basis of : (1) their ability to grow aerobically or anaerobically, with and without added carbon dioxide; (2) their ability to utilize various sugars; (3) their fermentation products from glucose; (4) certain physiological properties. The results of these experiments are presented here.

\section{METHODS}

\section{Strains of organisms}

Twelve strains of Actinomyces spp. and four of Lactobacillus bifidus were studied. The strains of Actinomyces spp. were those described previously (Howell \& Pine, 1956), except that the bovine isolates, strains 278 and 284, were not included in the present study. Cultures 306 and 307 were avian strains of $L$. bifidus obtained through the courtesy of Mr Morrison Rogosa, National Institute of Dental Research. Strains 308 and 309 were human isolates of $L$. bifidus described as 'Timberlaine' and 'Jackson' strains, respectively, by Norris, Flanders, Tomarelli \& György (1950), and were obtained from Dr Paul György, Department of Pediatrics, University of Pennsylvania Hospital. Cultures of Actinomyces spp. were maintained as described previously (Howell \& Pine, 1956); those of L. bifidus were maintained on the acetate medium of Norris et al. (1950) modified by the omission of pancreatin and sorbitan mono-oleate as recommended by Norris (personal communication).

\section{General methods}

The procedures for the growth and preparation of inoculum for all cultures and measurements of growth were those described earlier (Howell \& Pine, 1956). To study growth anaerobically in the absence of carbon dioxide, a pyrogallol $+\mathrm{KOH}(10 \%, \mathrm{w} / \mathrm{v})$ seal was used; to measure growth aerobically in the presence of increased carbon dioxide, a $10 \%$ (w/v) $\mathrm{Na}_{2} \mathrm{CO}_{3}+\mathrm{m}-\mathrm{KH}_{2} \mathrm{PO}_{4}$ seal was used. In either case five drops of each reagent were used per growth tube. For studies on growth in air, the cotton plug and rubber stopper were replaced by an aluminium cap. In the experiments in which oxygen tolerance or carbon dioxide requirements were studied, all cultures were incubated at $37^{\circ}$ on a rotary shaker as described previously (Howell \& Pine, 1956). With the conditions of shaking under which such cultures were incubated in the presence or absence of added carbon dioxide, methylene blue ( 2 drops of a $10^{-4}$ dilution $/ 5 \mathrm{ml}$. medium) was not reduced. In those cultures in which growth was obtained in the presence of oxygen, serial transfers were made when the optical density reached $\mathbf{0 . 5 0 0}$ or greater. For other studies anaerobic cultures were incubated stagnant inasmuch as shaking did not appear significantly to affect growth of actinomycetes (Howell \& Pine, 1956).

Unless stated otherwise, the medium used for all comparative growth experiments was the liquid defined medium with starch and Casitone described 
by Howell \& Pine (1956) containing $0.5 \%(w / v)$ sugar. For fermentation analyses the same medium with 0.5 or $1.0 \%(w / v)$ glucose and either casein hydrolysate, Casitone, or Casitone supplemented with $0.5 \%(w / v)$ yeast extract was used. The inoculum was grown anaerobically in the $0.5 \%(w / v)$ glucose Casitone medium.

\section{Cultural methods for fermentation analyses}

As reported previously, several of the Actinomyces strains show poor growth at $\mathrm{pH} 7 \cdot 0$ in the casein hydrolysate medium, although excellent growth is obtained at $\mathrm{pH}$ 6.5. Consequently, in cases where accurate carbon dioxide

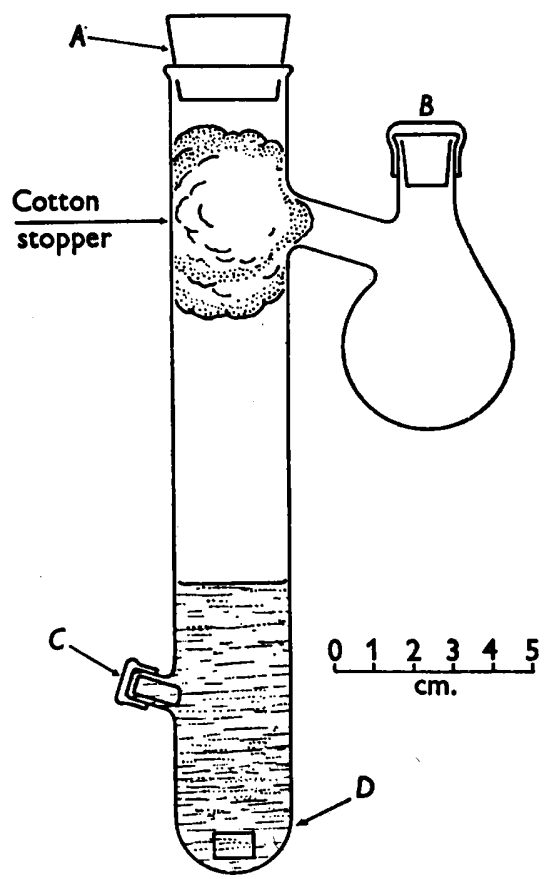

Fig. 1. Diagram of fermentation tube used for carbon dioxide analyses.

determinations were to be made a system was necessary which would allow the addition of gaseous carbon dioxide at $\mathrm{pH} 6.5$ and analyses of residual carbon dioxide without loss to, or contamination from, the air. Initially, $100 \mathrm{ml}$. volumetric flasks filled to the mark were sealed with sterile vaccine bottle stoppers. By the use of hypodermic needles pushed through the stoppers, the air phase was replaced with a $95 \% \mathrm{~N}_{2}+5 \% \mathrm{CO}_{2}(\mathrm{v} / \mathrm{v})$ mixture. When growth had apparently ceased, carbon dioxide-free $\mathrm{NaOH}$ was injected through the stopper until the medium was alkaline, and a sample was then withdrawn for analysis. As will be described later, such flasks, although usable, were not entirely satisfactory. Good growth was more consistently obtained with the type of tube shown in Fig. 1, containing $25-30 \mathrm{ml}$. of medium. In this case, after the medium was inoculated, the cotton stopper, used in autoclaving before 
the introduction of the medium, was pushed into the tube to block the side arm orifice and the tube was sealed with a no. 4 rubber stopper, $A$. A no. 20 hypodermic needle attached by a rubber hose to a vacuum pump was then pushed through the vaccine stopper, $B$, and the system evacuated for 1-2 min. The needle was withdrawn and $3 \mathrm{ml}$. of a pyrogallol $+\mathrm{H}_{2} \mathrm{SO}_{4}$ solution $(30 \mathrm{~g}$. pyrogallol dissolved in and made to $100 \mathrm{ml}$. with $\mathrm{N}-\mathrm{H}_{2} \mathrm{SO}_{4}$ ) were introduced with a syringe into the side bulb through $B$. Next 4 ml. of $10 \% \mathrm{Na}_{2} \mathrm{CO}_{3}(\mathrm{w} / \mathrm{v})$ solution were injected slowly into the bulb. The cotton stopper prevents contamination by vapour formed by the release of carbon dioxide. At the end of the growth period sufficient carbon dioxide-free $\mathrm{NaOH}$ to make the medium pH 9 or greater was injected directly into the medium through the stopper at $C$. The tube was incubated overnight or longer at $5^{\circ}$ to absorb the carbon dioxide into the medium. One $\mathrm{ml}$. samples were then withdrawn with an Ostwald-Van Slyke pipette with stopcock and rubber tip for determination of the final carbon dioxide content of the medium. In this type of tube the granules of Actinomyces strains rapidly settled to the bottom and growth was localized there. Therefore a magnet, $D$, was used in conjunction with a magnetic stirrer to mix the culture sediment throughout the medium several times each day. Uninoculated controls were used to determine the initial carbon dioxide concentration. In one experiment four replicate determinations of the initial carbon dioxide present in uninoculated controls gave values of $25 \cdot 62,24 \cdot 25,26 \cdot 71$, and $24 \cdot 73 \mu \mathrm{mole} / \mathrm{ml}$.

In some cases, where carbon dioxide was not determined, cultures were grown in $25 \times 200 \mathrm{~mm}$. test tubes containing 25 or $30 \mathrm{ml}$. of medium with a pyrogallol $+\mathrm{Na}_{2} \mathrm{CO}_{3}$ seal.

\section{Chemical methods}

Nitrate reduction was tested on horse meat infusion broth containing $1 \%$ trypticase, $0.5 \% \mathrm{NaCl}$ and $0.1 \% \mathrm{KNO}_{3}$. Qualitative nitrite determinations were made daily for 7 days (Manual of Methods for Pure Culture Study of Bacteria, 1946); residual nitrate was determined after 7 days incubation. Gelatin liquefaction was tested after 10 days incubation on the horse meat infusion broth containing $10 \%(\mathrm{w} / \mathrm{v})$ gelatin. Cultures on litmus milk were incubated for 10 days. Catalase was determined on colonies of actinomycetes grown for 7 days on brain heart infusion agar plates by adding 1-2 drops of a freshly prepared $10 \%(\mathrm{v} / \mathrm{v})$ solution of Superoxol (Merck and Co., Reagent, hydrogen peroxide $30 \%$ ) and observing gas formation. Cells of Candida albicans served as a positive control. All cultures for determination of nitrate reduction, gelatin liquefaction, action on litmus milk and catalase reaction were incubated anaerobically in Brewer jars with $95 \% \mathrm{~N}_{2}+5 \% \mathrm{CO}_{2}$ at $37^{\circ}$.

Carbon dioxide was measured by the method of Peters \& Van Slyke (1932) or with the Warburg apparatus. Initial and residual glucose were determined by the method given by Umbreit, Burris \& Stauffer (1949). Ethanol was identified qualitatively by diffusion into dichromate (Winnick, 1942) and the acid formed by its Duclaux value. Quantitative determinations of acetoin were made by the procedure of Westerfeld (1945). Quantitative estimation of 
glycerol in several fermentations by the procedure of Smith (1950) showed no significant formation of this compound. Tests for organic compounds not mentioned above were made by the dichromate oxidation procedure of Johnson (1949). Formic and acetic acids were identified qualitatively as a mixture by their Duclaux values and were then identified by paper chromatography and $\boldsymbol{R}_{f}$ values by the procedure of Kennedy \& Barker (1951). Formate was also shown to be present at the correct $R_{f}$ by spraying with $5 \%$ (w/v) ammoniacal $\mathrm{AgNO}_{3}$. Formic and acetic acids formed by strains of Actinomyces spp. were then determined quantitatively by the procedure of Friedemann (1938) as modified by Rabinowitz \& Barker (1956). Formic acid formed by strains of Lactobacillus bifidus in the acetate medium (Norris et al. 1950) containing glucose or lactose, was identified and estimated in acid steam distillate by the formic acid hydrogenlyase method of Gest (1952). Four ml. Warburg vessels were used. It was estimated in other media by the procedure of Rabinowitz \& Barker (1956).

Succinic acid was identified as a product of glucose fermentation by actinomycetes by fermenting glucose- ${ }^{14} \mathrm{C}$ with strains 279 and 295 . Isolation of an unknown radioactive non-volatile acid was accomplished by paper chromatography (Block, Durrum \& Zweig, 1955) and subsequent radioautographs. Its identity was indicated by a dilution and spreading of the radioactive spot upon the addition of unlabelled succinic acid to paper chromatograms. Ethanol + ammonia (Kennedy \& Barker, 1951) and methanol + pyridine (Redfield, 1953) were used as solvents. The unknown compound was separated from lactic acid by the procedure of Phares, Mosbach, Denison \& Carson(1952). Titration values and radioactivity determinations on the effluents of a Celite column showed a direct correspondence of the peak with known succinic acid. Separation from lactic acid was also accomplished by eluting the radioactive strip from paper chromatograms. The separated succinic acid fractions were assayed by the succinoxidase procedure of Umbreit et al. (1949) using $5 \mathrm{ml}$. Warburg vessels. Subsequently, fermentation analyses for succinic acid were made directly on the non-volatile ether-extractible acid fraction. Lactic acid did not interfere with the determination.

Lactic acid was isolated and identified as the zinc salt according to the procedure of Pederson, Peterson \& Fred (1926). It was determined quantitatively by the method of Barker \& Summerson (1941). The oxidation-reduction indices (redox values) were calculated according to the method of Neish (1950).

\section{RESULTS}

Comparison of media for growth of Lactobacillus bifidus

Preliminary experiments indicated that the rates of growth of each of the four strains of Lactobacillus bifidus in the liquid medium with starch (Casitone and $0.5 \%$ lactose; Howell \& Pine, 1956) were essentially comparable to those obtained in the acetate lactose medium of Norris et al. (1950) (Fig. 2). Furthermore, although the amount of growth obtained with the human bifid strains was less than that obtained on the lactose medium of Norris et al. 
(1950), the amount of growth of the avian strains was significantly greater on the lactose Casitone starch medium than on the lactose medium. Gram stains of bifid cultures 308 and 309 on the former medium showed more 'straight rod' forms than were usually obtained on the medium. However, subcultures on to the lactose agar of Norris et al. (1950) from cultures of strains 308 and 309 on the lactose Casitone starch medium, made after maximum growth was obtained, yielded only the typical 'bifid type' colonies described by Norris et al. (1950). Gram stained films of these colonies showed consistently and almost exclusively bifid morphology. Similar results were obtained when glucose was substituted for lactose in the Casitone medium, with the exception that strain 306 failed to grow on Casitone glucose. Since the casitone starch medium appeared to be a satisfactory medium for the growth of all four strains of $L$. bifidus, did not induce 'mutations' in these cultures, and had previously been shown to support excellent growt th of all strains of Actinomyces spp., it was chosen as the basic medium for the comparative study of cultures of $L$. bifidus and Actinomyces.

Oxygen tolerance and carbon dioxide requirements of strains of Actinomyces spp. and Lactobacillus bifidus

From Table 1, it is seen that all cultures of Actionyces spp. and Lactobacillus bifidus required carbon dioxide for anaerobic growth in the liquid glucose Casitone starch medium. Fou" of the six Actinomyces capable of

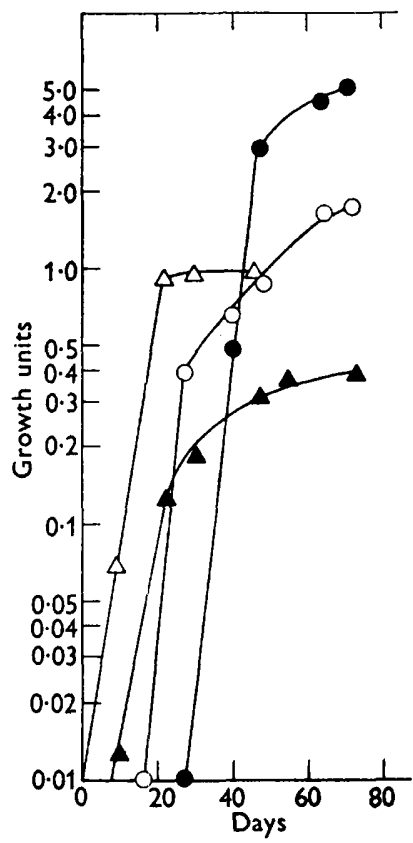

Fig. 2. Rate of growth of human (308) and avian (307) strains of Lactobacillus bifidus in the lactose medium of Norris et al. (1950) and on the lactoseCasitone medium. Strain 307: $\Delta, \triangle$; strain 308: $\bigcirc, O$; $\Delta, \mathbf{O}=\mathbf{1} \cdot 75 \%$ lactose, medium; $\triangle, O=\mathbf{0 . 5} \%$ lactose, Casitone medium. aerobic growth under these conditions and the single strain of $L$. bifidus capable of limited aerobic growth required carbon dioxide for such growth. Subsequent experiments, however, indicated that growth of strain 296 in air without carbon dioxide, and of strain 282 in air + carbon dioxide was not a constant finding.

Of the Actinomyces capable of aerobic growth on the first transfer, five appeared capable of continuous transfer in air of increased carbon dioxide tension. These cultures gave as much or more (in several instances twice as much) growth aerobically as they did anaerobically with carbon dioxide (Table 1). In those cultures grown aerobically or in air plus carbon dioxide on which a final $\mathrm{pH}$ value was determined, the terminal $\mathrm{pH}$ value was found to be approximately $5 \cdot 0-6 \cdot 1$ as compared to about $4 \cdot 5$ usually obtained in cultures grown anaerobically. Strains 279, 282 and 296 showed no 
decrease in rate or amount of anaerobic growth after four to six consecutive aerobic transfers (with added carbon dioxide). These cultures, particularly those which grew aerobically, were examined by Gram reaction and by wet mounts made at the period of maximum growth. In no instance in the reported experiments was there observed any indication of contamination or gross change in morphology. In other experiments (Howell, unpublished), colonies of strains 279 and 296 developed on plates of this medium containing $1.5 \%(\mathrm{w} / \mathrm{v})$ agar in air $+5 \%(\mathrm{v} / \mathrm{v})$ carbon dioxide. These colonies, though

Table 1. Amount of growth of strains of Actinomyces spp. and Lactobacillus bifidus obtained anaerobically and aerobically in the presence and absence of added carbon dioxide

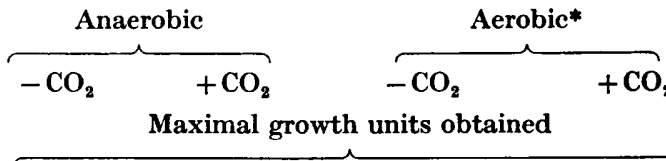

\begin{tabular}{|l} 
Actinomyces spp. \\
261 \\
262 \\
263 \\
279 \\
281 \\
282 \\
283 \\
286 \\
287 \\
295 \\
296 \\
L. bifidus \\
307 \\
308 \\
309
\end{tabular}

$\begin{array}{llll} & & & \\ \text { None } & 2.90 & 0.10(1) & 2.68(1) \\ \text { None } & 1.83 & 0.14(1) & 0.12(1) \\ \text { None } & 2.25 & 0.10(1) & 3.23(5) \\ \text { None } & 3.00 & 3.60(5) & 5.60(5) \\ \text { None } & 2.32 & 0.11(1) & 0.47(1) \\ \text { None } & 2.75 & 0.07(1) & 4.40(4) \\ \text { None } & 1.60 & 0.02(1) & 0.06(1) \\ \text { None } & 3.50 & 0.13(1) & 6.20(6) \\ \text { None } & 0.80 & 0.13(1) & 0.13(1) \\ \text { None } & 2.63 & 0.20(1) & 0.52(1) \\ \text { None } & 2.35 & 0.71(2) & 4.48(5) \\ & & & \\ \text { None } & 1.40 & 0.00 & 0.70(1) \\ \text { None } & 3.11 & 0.00 & 0.12(1) \\ \text { None } & 3.17 & 0.00 & 00\end{array}$

* The numbers in parentheses indicate tho number of consecutive transfers in which growth was obtained and the maximum growth (expressed as growth units) obtained on the first transfer.

fewer in number than on similar plates incubated in an atmosphere of $5 \% \mathrm{CO}_{2}+95 \% \mathrm{~N}_{2}(\mathrm{v} / \mathrm{v})$ were identical in colony morphology with those developed on the plates incubated anaerobically. Similar studies (Pine, unpublished) with strain 296 using large agar slants and both the potassium phosphate + sodium carbonate, or pyrogallol+sodium carbonate seals described above, gave identical colonies and cell morphology. From these results, and those presented in Table 1, it would appear that under these conditions some strains of the genus Actinomyces are facultative anaerobes, whereas others are obligate anaerobes or microaerophils.

A single strain of Lactobacillus bifidus (307) showed some aerobic growth in the presence of added carbon dioxide, but the amount was but half that obtained anaerobically with carbon dioxide and did not continue on the second transfer (Table 1). The other two lactobacillus cultures showed no aerobic growth. These cultures would appear to be anaerobes or microaerophils. 
Cultures of Lactobacillus bifidus were also tested for an anaerobic carbon dioxide requirement on the same medium with $0.5 \%(\mathrm{w} / \mathrm{v})$ lactose. Of the four strains tested, only the avian strains (306 and 307) grew anaerobically on lactose without added carbon dioxide. However, only half the amount of growth was obtained under these conditions as was obtained on this medium with added carbon dioxide. It would appear, therefore, that with L. bifidus the medium used may affect the requirement for carbon dioxide.

\section{Growth of Lactobacillus bifidus and Actinomyces spp. on sugars}

Rose, Luchi, Avery, Norris \& György (1953) reported that human strains of Lactobacillus bifidus utilized the disaccharides lactose and maltose more readily than glucose and implied that this finding might be of value in differentiating L. bifidus from its straight rod variants and L. acidophilus. Comparisons were

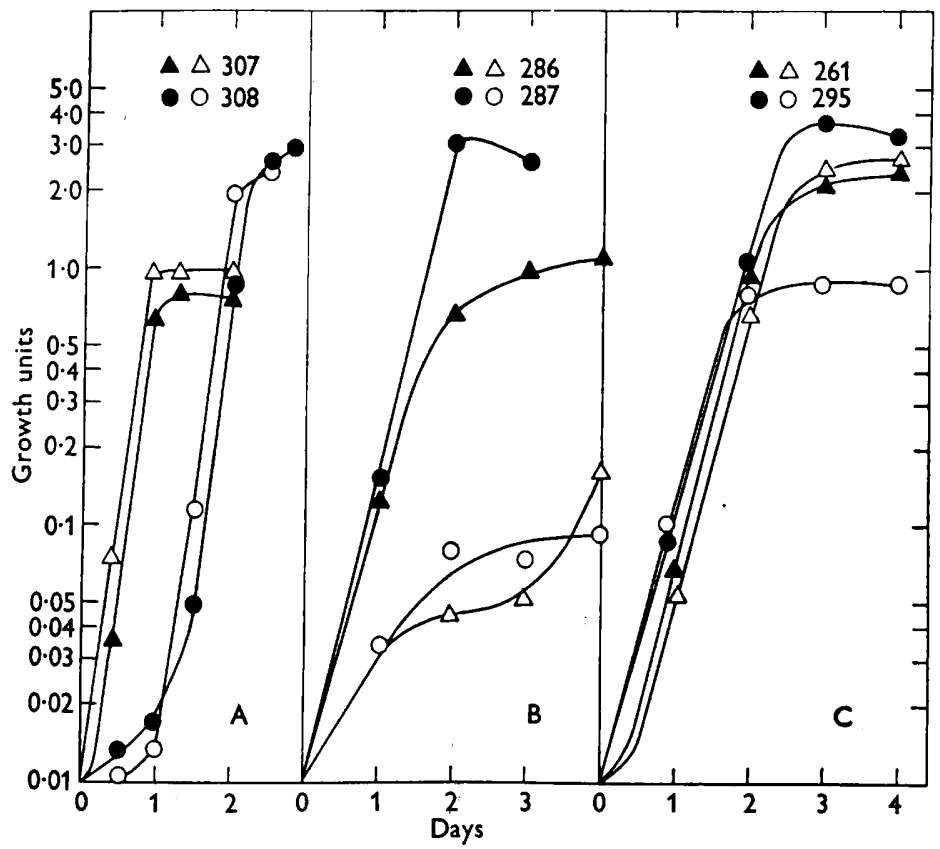

Fig. 3. Rate of growth of strains of Lactobacillus bifidus and Actinomyces spp. on glucose and lactose. A: L. bifidus; B, C: Actinomyces spp.;,$\Delta=$ glucose; $O, \Delta=$ lactose.

made, therefore, of the relative utilization of these three sugars by strains of $\boldsymbol{L}$. bifidus and the actinomycetes to determine whether or not these two groups of organisms behaved similarly under these conditions.

Under the conditions of this experiment, it was found that the rates and amounts of growth of all lactobacilli tested were, in general, similar on lactose and glucose except for strain 306 which did not grow on glucose (Fig. 3A). In some instances the rates of growth were slightly higher on lactose but these results were not consistent. However, growth on glucose was never significantly greater than on lactose. In a single experiment, rates 
of growth of strains 307,308 and 309 were slightly higher on maltose than on glucose but the difference was not regarded as significant. Strain 306 was not tested on maltose.

On the other hand, most cultures of the Actinomyces were more 'active' on glucose than on lactose. One group of strains $(277,279,286$ and 287) grew more slowly and erratically with lactose as a substrate than with glucose and the final amounts of growth were much greater with glucose (Fig. 3B). A second group (strains 295 and 296; showed equal rates of growth on the two sugars but the amount of growth on glucose was three to four times that obtained on lactose (Fig. 3C). Other strains (261, 263, 282 and 283) showed equal rates and amounts of growth on the two sugars (Fig. $3 \mathrm{C}$ ). In no instance, however, was growth on lactose considered to be superior to that on glucose. Results with maltose were essentially identical with those on glucose with each of the ten strains tested.

The relative ability of these two groups of organisms (except strain 306) to utilize other carbohydrates and pyruvate and gluconate as carbon sources was then tested. Carbohydrates employed were arabinose, mannitol, mannose, raffinose, rhamnose, ribose, salicin and sucrose. In general, no single one of these substrates showed a clear differentiation of lactobacilli as a group from the actinomycetes as a group (Table 2). Little or no growth of either group was obtained on the basal medium alone.

In addition to the results reported above, the actinomycetes and Lactobacillus bifidus were tested for the presence or absence of certain other biological properties. All strains of each group of organisms were found to be catalasenegative; none liquefied gelatin; all eleven strains of Actinomyces spp. were found to reduce nitrates to nitrites, but none of the lactobacilli strains possessed this ability; production of acetylmethylcarbinol was variable in both groups, apparently being dependent on the medium; and finally, both groups showed similar activity on litmus milk in that, in general, they produced acid and showed some reduction, both properties varying in extent, dependent on the strain.

\section{Studies on the fermentation of glucose by Actinomyces and Lactobacillus bifidus}

The results of analyses of fermentations of seven Actinomyces strains on $1 \%(\mathrm{w} / \mathrm{v})$ glucose in the basal medium prepared with casein hydrolysate are given in Table 3. In this medium and under the conditions employed, c. $90-100 \%$ of the carbon of the glucose fermented by these strains was determined as lactic acid. All cultures, however, produced small amounts of formic and acetic acids (3.5-11.8\% of the glucose fermented). A compound tentatively identified as ethanol accounted for a maximum of $2 \%$ of the glucose fermented. Although acetylmethylcarbinol was found in trace amounts in other media, none was formed in the fermentations presented in Table 3. Starch, which is present in the medium at a concentration of $0.05 \%$ $(\mathrm{w} / \mathrm{v})$, is known to support a small amount of growth of at least strains $27 \%$, 279, 286 and 287; its presence is accounted for in the calculations of percentage 


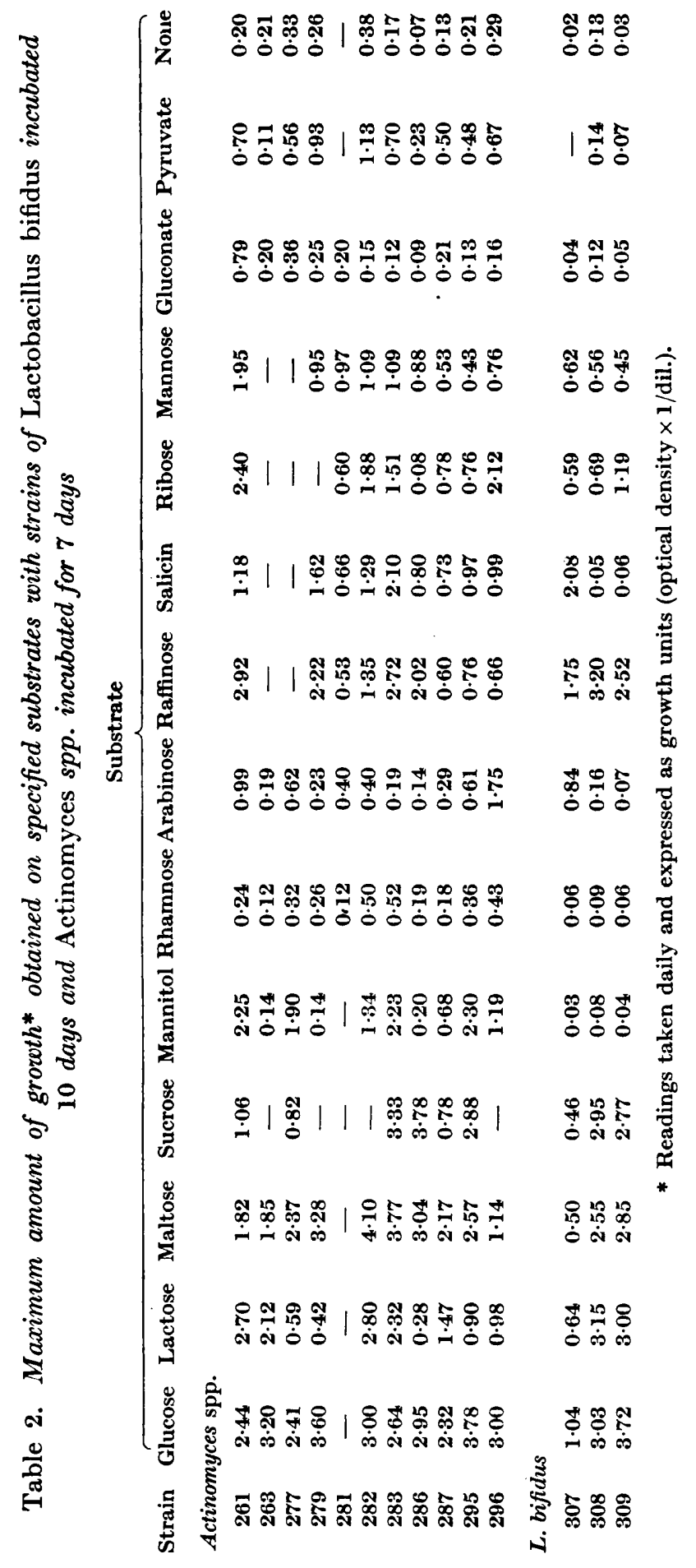


carbon recovered. In general carbon recoveries in this medium were high. The values obtained for carbon dioxide are questionable since the determinations employed the Warburg apparatus and were susceptible to contamination with carbon dioxide from the air. No fermentation analysis gave a satisfactory redox bslance. Because of the small concentration of reduced or oxidized products, this was not considered important.

Table 3. Analysis of glucose $(1.0 \%$, w/v) fermentations by strains of Actinomyces spp. in basal medium with casein hydrolysate in $100 \mathrm{ml}$. volumetric flasks filled to the mark, and flushed 1-2 min. with $95 \% \mathrm{~N}_{2}-5 \% \mathrm{CO}_{2}$ to remove air

\begin{tabular}{|c|c|c|c|c|c|c|c|}
\hline \multirow[t]{2}{*}{ 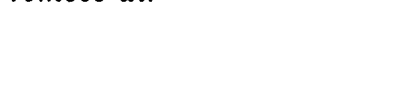 } & \multicolumn{7}{|c|}{ Strain number } \\
\hline & 277 & 278 & 281 & 282 & 286 & 287 & 295 \\
\hline & \multicolumn{7}{|c|}{$\mu \mathrm{mole} / \mathrm{ml}$. } \\
\hline Glucose fermented & $\mathbf{3 2} \cdot \mathbf{4}$ & $27 \cdot \mathbf{8}$ & $20 \cdot 6$ & $29 \cdot 1$ & $30 \cdot 1$ & $28 \cdot 5$ & $19 \cdot 0$ \\
\hline \multicolumn{8}{|l|}{ Products } \\
\hline Carbon dioxide & 0.2 & $0 \cdot 6$ & 0.0 & 0.8 & 0.5 & 0.0 & 0.4 \\
\hline Formic acid & $3 \cdot 2$ & $3 \cdot 6$ & $4 \cdot 2$ & $3 \cdot 9$ & $2 \cdot 4$ & $4 \cdot 7$ & 4.5 \\
\hline Acetic acid & $1 \cdot 7$ & $1 \cdot 7$ & $2 \cdot 1$ & $1 \cdot 7$ & 0.7 & $2 \cdot 7$ & $3 \cdot 8$ \\
\hline Lactic acid & $64 \cdot 4$ & $53 \cdot 2$ & $41 \cdot 0$ & $57 \cdot 1$ & 58.5 & $42 \cdot 3$ & $\mathbf{3 8} \cdot 1$ \\
\hline Ethanol & - & $1 \cdot 2$ & - & - & 1.5 & $1 \cdot 8$ & $0 \cdot 7$ \\
\hline Percentage carbon recovered* & $101 \cdot 5$ & $98 \cdot 8$ & $103 \cdot 6$ & $99 \cdot 7$ & $98 \cdot 6$ & $96 \cdot 4$ & $108 \cdot 3$ \\
\hline Redox value & - & $\mathbf{2 \cdot 0 0}$ & - & - & $1 \cdot 13$ & 1.80 & $3 \cdot 78$ \\
\hline Percentage glucose fermented & $57 \cdot 9$ & $49 \cdot 1$ & $37 \cdot 0$ & $\mathbf{5 2 \cdot 4}$ & $\mathbf{5 4} \cdot \mathbf{2}$ & $42 \cdot 4$ & $\mathbf{3 4 \cdot 2}$ \\
\hline
\end{tabular}

* Values of percentage carbon recovered have been corrected for the presence of $0.05 \%(w / v)$ starch assuming utilization of the starch and weight to weight equivalence of starch to glucose.

In an attempt to determine whether or not the composition of the medium would significantly affect the products of glucose fermentations, three strains of Actinomyces were grown in the casein hydrolysate medium $(1 \%$, w/v, glucose) and in the Casitone medium supplemented with $0.5 \%(\mathrm{w} / \mathrm{v})$ yeast extract, with and without $0.5 \%(\mathrm{w} / \mathrm{v})$ glucose. The results obtained are given in Table 4. A small amount of growth and fermentation occurred in the Casitone yeast-extract medium without glucose, but this growth was accounted for by the disappearance of reducing substances from the medium. Growth of these strains in the two sugar-containing media showed a wide diversity in the amount of lactic acid formed, the ratio of lactic acid to volatile acid formed, and in the ratio of formic to acetic acid formed. The amount of lactic acid formed in the casein hydrolysate medium was from 80 to $93 \%$ of the glucose fcrmented. In the Casitone yeast-extract medium, lactic acid accounted for $63-82 \%$ of the glucose fermented. Furthermore, carbon recoveries in the latter medium were significantly lower for two strains than that obtained in the casein hydrolysate medium.

In other experiments, carbon recoveries in the Casitone medium were generally lower than those obtained using casein hydrolysate. For example, analysis of fermentations of strains 277 and 282, in the Casitone medium with 
Comparison of Actinomyces spp. with L. bifidus

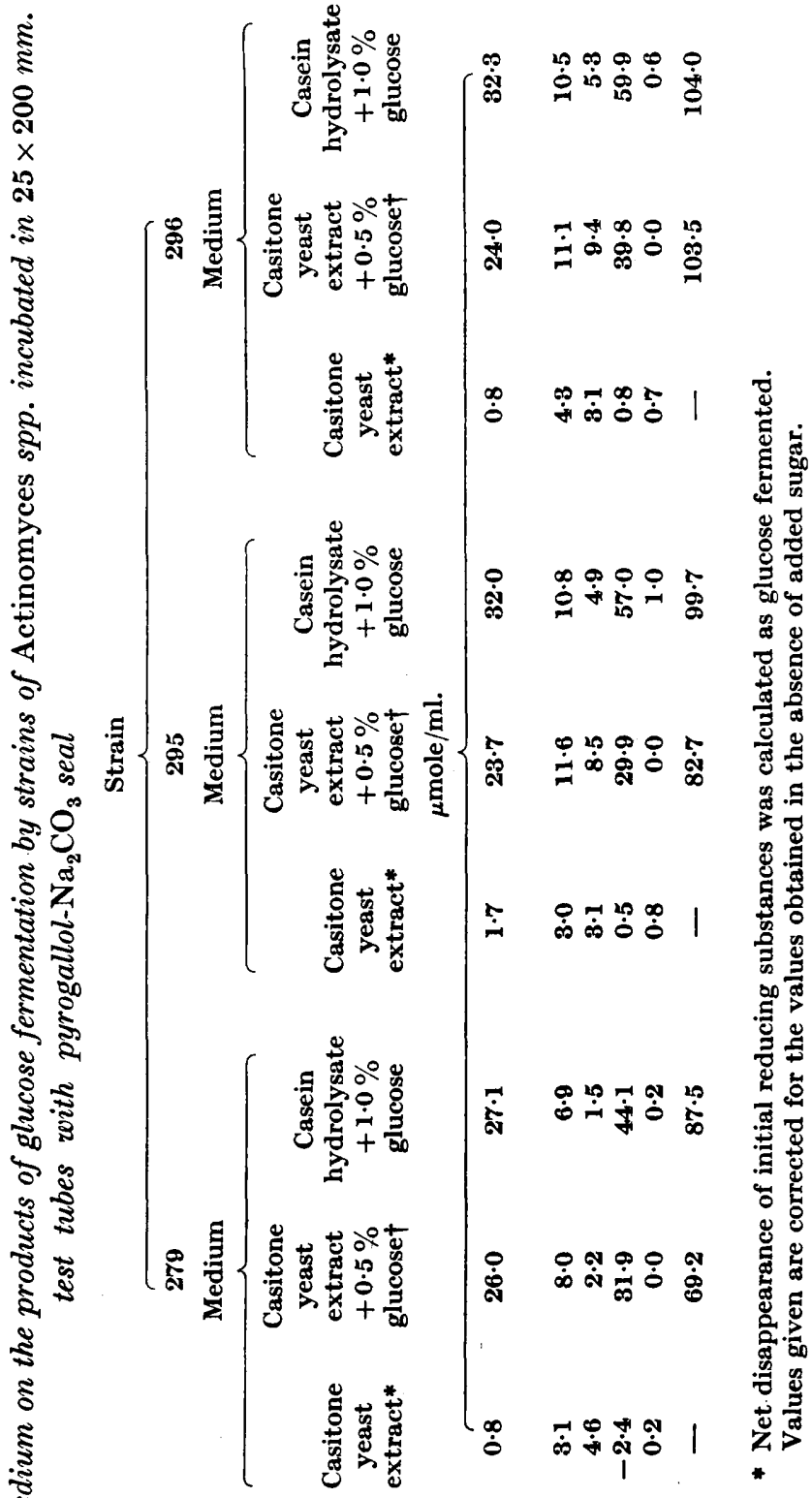

है

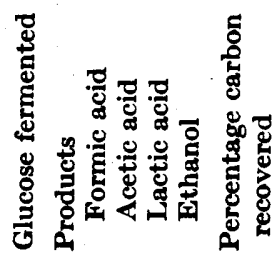

G. Microb. xv 
and without glucose, gave essentially the same results obtained with strain 295. Carbon recoveries in the presence of added sugar were $86 \%$ in all cases. These results suggested that an unknown product was being formed. Subsequently, analyses of fermentations of glucose- ${ }^{14} \mathrm{C}$ with strains 279 and 295 in the Casitone yeast-extract medium revealed the formation of significant amounts of succinic acid. No additional products were found.

Table 5. Analysis of glucose (1\%) fermentations by specified strains of Actinomyces spp. and Lactobacillus bifidus in basal medium with Casitone and $1.0 \%(w / v)$ glucose

\begin{tabular}{|c|c|c|c|c|c|c|c|c|}
\hline & \multicolumn{5}{|c|}{$\begin{array}{c}\text { Actinomyces spp. } \\
\text { Strain }\end{array}$} & \multicolumn{3}{|c|}{$\begin{array}{l}\text { L. bifidus } \\
\text { Strain }\end{array}$} \\
\hline & 277 & 279 & 282 & 295 & 296 & 307 & 308 & 309 \\
\hline & \multicolumn{8}{|c|}{$\mu$ mole used or formed per ml. } \\
\hline Glucose fermented & $25 \cdot 2$ & $\mathbf{2 4} \cdot \mathbf{9}$ & $24 \cdot 3$ & $26 \cdot 6$ & $25 \cdot 4$ & $32 \cdot 9$ & $49 \cdot 2$ & $47 \cdot 6$ \\
\hline $\begin{array}{l}\text { Carbon dioxide } \\
\text { utilized }\end{array}$ & $4 \cdot 5$ & $8 \cdot 9$ & $4 \cdot 7$ & $8 \cdot 7$ & $10 \cdot 8$ & $11 \cdot 2$ & $4 \cdot 8$ & 0.8 \\
\hline Products & & & & & & & & \\
\hline Formic acid & $6 \cdot 0$ & $7 \cdot 9$ & $5 \cdot 8$ & $7 \cdot 8$ & $11 \cdot 5$ & $10 \cdot 4$ & $5 \cdot 8$ & $7 \cdot 5$ \\
\hline Acetic acid & $3 \cdot 4$ & $3 \cdot 2$ & $5 \cdot 4$ & $6 \cdot 3$ & $12 \cdot 0$ & $54 \cdot 8$ & $66 \cdot 7$ & $70 \cdot 4$ \\
\hline Lactic acid & $44 \cdot 3$ & $42 \cdot 1$ & $38 \cdot 2$ & $\mathbf{3 7} \cdot \mathbf{1}$ & $24 \cdot 5$ & $\mathbf{2 2} \cdot 1$ & $46 \cdot 3$ & $\mathbf{3 8 \cdot 9}$ \\
\hline Succinic acid & $\mathbf{3 \cdot 0}$ & $4 \cdot 7$ & $6 \cdot 1$ & $8 \cdot 6$ & $12 \cdot 8$ & Trace & $\mathbf{3 \cdot 6}$ & $\mathbf{1 \cdot 2}$ \\
\hline $\begin{array}{l}\text { Percentage carbon } \\
\text { recovered }\end{array}$ & $101 \cdot 3$ & $100 \cdot 7$ & $108 \cdot 4$ & $98 \cdot 7$ & $98 \cdot 1$ & $89 \cdot 4$ & $97 \cdot 3$ & $97 \cdot 4$ \\
\hline Redox value & $1 \cdot 00$ & 0.77 & $1 \cdot 26$ & 0.94 & $1 \cdot 12$ & $0 \cdot 46$ & 0.98 & $5 \cdot 40$ \\
\hline $\begin{array}{l}\text { Percentage glucose } \\
\text { fermented }\end{array}$ & $45 \cdot 4$ & $44 \cdot 8$ & $43 \cdot 8$ & $47 \cdot 9$ & $45 \cdot 8$ & $59 \cdot 2$ & $88 \cdot 6$ & $85 \cdot 7$ \\
\hline
\end{tabular}

With the change in fermentation noted in the Casitone yeast-extract medium, the necessity for accurate redox balances was emphasized. It had been observed that cultures grown in volumetric flasks from which oxygen was removed by gassing with $95 \% \mathrm{~N}_{2}+5 \% \mathrm{CO}_{2}$ had long lag periods, gave small amounts of growth and often required re-inoculation to obtain growth. Occasionally similar results were obtained with these flasks using a pyrogallol $+\mathrm{Na}_{2} \mathrm{CO}_{3}$ seal. However, cultures in the $25 \times 200 \mathrm{~mm}$. test-tubes sealed with pyrogallol $+\mathrm{Na}_{2} \mathrm{CO}_{3}$ seals (12 to 15 drops each) invariably gave good growth. These results, together with the fact that carbon dioxide was known to be required by all strains for anaerobic growth, suggested that carbon dioxide was a limiting factor, and that net fixation of carbon dioxide was occurring. Consequently, the fermentation flasks illustrated in Fig. 1 were used with the Van Slyke blood gas apparatus to determine the initial and final carbon dioxide content of the medium. The results presented in Table 5 show that there is a significant net carbon dioxide fixation by Actinomyces strains 279, 295 and 296, and probably lesser carbon dioxide fixation by strains 277 and $\mathbf{2 8 2}$, and suggest that carbon dioxide may not be a product of glucose fermentation as indicated by the results in Table 3. 
The results in Table 5 show that, in general, the products formed by strains of Actinomyces and Lactobacillus bifidus on the glucose Casitone medium are identical but differ quite markedly in the relative amounts of acetic acid formed. In these fermentations, the acetic acid formed by actinomycetes accounted for $4 \cdot 3-15 \cdot 8 \%$ of the glucose fermented, whereas that formed by the lactobacilli was from $45 \cdot 2$ to $54.5 \%$ of the glucose utilized. Furthermore, of the total glucose added to the medium, the actinomycetes fermented from $43 \cdot 8$ to $47 \cdot 9 \%$, whereas the lactobacilli utilized from $59 \cdot 2$ to $88 \cdot 6 \%$. All cultures showed an apparent fixation of gaseous carbon dioxide, although in all probability the value given for strain 309 is in error. Strain 307 of L. bifidus formed but a trace of succinic acid. Similarly, in other fermentations done with $L$. bifidus, strain 308 , succinate was not found.

Negroni \& Fischer (1944) and Norris et al. (1950) have shown that lactobacilli cultures isolated from human sources form $\mathrm{L}(+)$ lactic acid. The type of lactic acid formed by actinomycetes has not been reported. Cultures of strains 277, 279, 282 and 295 were harvested and the lactic acid formed from glucose was isolated as the zinc salt. $4 \%$ solutions $(w / v)$ of the anhydrous salts gave specific rotations of $-5 \cdot 35$ to $-8 \cdot 10$ (specific rotation of a $4 \%$ solution of active zinc lactate was reported by Pederson et al. (1926) to be $-8 \cdot 25)$. The $4 \%(\mathrm{w} / \mathrm{v})$ solutions of zinc lactate tested were found to be contaminated with a maximum of $0.7 \%(\mathrm{w} / \mathrm{v})$ succinic acid. The rotations reported are based on lactic acid concentrations determined by the method of Barker \& Summerson (1941). It would therefore appear that $\mathrm{L}(+)$ lactic acid is formed by these strains of Actinomyces spp. but small amounts of $\mathrm{D}(-)$ lactic acid may also be formed.

\section{DISCUSSION}

It was indicated above that strains representative of Actinomyces bovis as described by Erikson (1940) and Thompson (1950) were not included in the present study. Initially two cultures typical of the description of $A$. bovis (Erikson, 1940; Thompson, 1950) were tested for growth on the basal medium used in these experiments (Howell \& Pine, 1956). Of these, one strain (284) gave satisfactory growth on this medium but unfortunately this strain was lost during the present investigation. The second strain (278) gave only a limited amount of growth on this medium and therefore was not used in the present study. Attempts were made to obtain other cultures similar to the above two bovine isolates. However, all such cultures available for study were found to be identical, in certain major characteristics (indole, $\mathrm{H}_{2} \mathrm{~S}$, and catalase production; action on milk and gelatin) with Corynebacterium acnes as described by Beerens (1953). It was therefore considered unwise to include these cultures in the present study.

Certain strains of Actinomyces spp. and Lactobacillus bifidus have been described previously as anaerobes or microaerophiles (Erikson, 1940; Gyllenberg, 1955); as requiring or being stimulated by carbon dioxide (Erikson, 1940; Rosebury, Epps \& Clark, 1944; Norris et al. 1950); of being capable of aerobic growth (Thompson \& Lovestedt, 1951 ; Veltre, Shorb \& Pelczar, 1953); 
of being able to grow in the presence of small amounts of oxygen (Rosebury et al. 1944; Norris et al. 1950); of being able to adapt to aerobic conditions (Ludwig \& Sullivan, 1952); or, in the case of $L$. bifidus, of being able to adapt to growth in air with the formation of 'straight' rod forms (Gyllenberg, 1955; Hayward, Hale \& Bisset, 1955). Erikson \& Porteous (1955) have also reported the conversion of a single 'rough' strain of $A$. israelii to a 'smooth' type more tolerant of oxygen. They found, however, that this apparent conversion was due to the presence in cultures of this strain of a facultatively anaerobic staphylococcus which affected both colony morphology and oxygen tolerance of the host strain.

The results reported here show quite clearly that some strains of actinomycetes may be facultative anaerobes, whereas others are microaerophils to obligate anaerobes. Carbon dioxide may or may not be required for growth in air, but is apparently required by all strains of actinomycetes for anaerobic growth under the conditions described above. Of the strains of Lactobacillus bifidus tested all required carbon dioxide for anaerobic growth. Only one of the three strains tested grew in air; the growth which was obtained was very limited in amount and carbon dioxide was required. Therefore, it would appear that these strains of $L$. bifidus are essentially microaerophils or anaerobes.

The value of the comparative rates of growth of Actinomyces spp. and Lactobacillus bifidus on glucose, maltose and lactose is questionable. 'It would appear that some Actinomyces strains grow slowly on lactose, must adapt to its utilization, or lack the ability of utilizing the sugar as efficiently as they do glucose. However, other strains appear to utilize lactose as efficiently as they do glucose or maltose (maltose was utilized as well as glucose by all Actinomyces strains tested). Therefore, the use of these sugars for the differentiation of $L$. bifidus from the genus Actinomyces would seem to have but limited value, would require exact determination of rates of growth, total cell yields, etc. Nevertheless, considering the results of Rose et al. (1953), György, Norris \& Rose (1954), Huhtanen (1955), and the results reported above, it would appear that lactose is the preferred sugar for growth of $\boldsymbol{L}$. bifidus, whereas glucose or maltose is the preferred sugar for Actinomyces spp.

In most instances, results obtained with Actinomyces show that lactic acid was the primary product of glucose fermentation regardless of the medium or conditions employed. In one case reported above (strain 296, Table 5) lactic acid accounted for only $43 \%$ of the glucose fermented; succinic, acetic, and formic acids accounted for the remaining carbon. Depending upon the strain and the medium used, other products were formed but in an amount seldom accounting for more than $20 \%$ of the glucose fermented.

Results obtained with the three strains of Lactobacillus bifidus show that lactic and acetic acids in approximately equal amounts (based on the glucose fermented) are the primary products of glucose fermentation, although trace amounts (4-7\% of the glucose fermented) of formic and succinic acids may also be formed. The formation of lactic and acetic acids as the major products of glucose fermentation by human lactobacilli has been reported previously by Orla-Jensen (1943), Negroni \& Fischer (1944), and by Norris et al. (1950). 
The identity of the compound identified as ethanol in the Actinomyces fermentations is questionable since the basal medium contained a small amount of ethanol as a solvent for thioctic acid. The values reported were obtained as small differences between the zero time and final determinations. Acetoin production varied with the medium used, and in general, the greater the concentration of yeast extract or Casitone, the greater the acetoin formation; no acetoin was found to be produced in the glucose casein hydrolysate medium. Acetoin was never formed in amounts sufficiently great to affect the quantitative aspect of the fermentation balances. No other products besides formic, acetic and succinic acids were found in any of the fermentations.

The relative proportion and amounts of the products formed by actinomycetes apparently may be influenced somewhat by the presence of crude organic substances in the medium. Erikson \& Porteous (1953) found that on a heart broth casein digest medium, Actinomyces strains produced lactic acid equivalent to only $30-60 \%$ of the glucose utilized; other products were not reported.

Changes in the character of fermentations due to changes in the medium or methods of handling the cultures have been described by Pappenheimer \& Shaskan (1944), Waring \& Werkman (1944), Bard \& Gunsalus (1950), and Hodges, Coolidge \& Harrison (1951).

Increased carbon dioxide concentrations have previously been shown to be beneficial to the growth of Actinomyces strains (Erikson, 1940; Rosebury et al. 1944). That strains of Lactobacillus bifidus require carbon dioxide for anaerobic growth on solid media has been reported by Norris et al. (1950). The fermentative data presented in Table 5 show a net carbon dioxide fixation by both groups of organisms. However, in some cases the values for carbon dioxide fixed as shown in Table 5 are within or closely approaching experimental error. A net fixation in these instances is only suggestive.

If one uses the fermentation data of Actinomyces strains 282 or 296, and Lactobacillus bifidus, strain 308, as given in Table 5, recognizing the limitations of the data, over-all reactions based on the stoichiometry for glucose utilization for these organisms would approximate the following equations:

Actinomyces spp.: (1) Glucose $\rightarrow 2$ lactic acid

(2) Glucose $+\mathrm{CO}_{2} \rightarrow$ formic acid + acetic acid + succinic acid

L. bifidus: (1) Glucose $\rightarrow 2$ lactic acid

(2) Glucose $+\mathrm{CO}_{2} \rightarrow$ formic acid + acetic acid + succinic acid

(3) Glucose $\rightarrow$ 3 acetic acid

The apparent absence of reaction 3 in Actinomyces spp. suggests a major metabolic difference between Actinomyces spp. and Lactobacillus bifidus.

The authors wish to express their appreciation to Mr C. L. Peacock and Mr W. C. Murphy, III, for their valuable technical assistance; and to Dr J. C. Rabinowitz, National Institute of Arthritis and Metabolic Diseases, who very generously supplied the formic acid hydrogenlyase preparation. 


\section{REFERENCES}

Bard, R. C. \& Gunsalus, I. C. (1950). Glucose metabolism of Clostridium perfringens: existence of a metallo-aldolase: $J$. Bact. 59, 387.

Barker, S. B. \& Summerson, W. H. (1941). The colorimetric determination of lactic acid in biological materials. J. biol. Chem. 138, 535.

Beerens, H. (1953). Étude comparative de six souches de bactéries anaérobies non sporulées: Actinomyces bovis A.T.C.C. 8373 (bovine), A. bovis A.T.C.C. 8374 (humaine), A. israeli var. liquefaciens, Corynebacterium acnes, Corynebacterium avidium, Corynebacterium liquefaciens. Ann. Inst. Pasteur, 84, 1026.

Block, R. J., Durrum, E. L. \& Zweig, G. (1955). In A Manual of Paper Chromatography and Paper Electrophoresis. New York: Academic Press, Inc.

Erikson, D. (1940). Pathogenic anaerobic organisms of the Actinomyces group. Spec. Rep. Ser., med. Res. Coun., Lond. no. 240.

Erikson, D. \& Porteous, J. W. (1953). The cultivation of Actinomyces israelii in a progressively less complex medium. J. gen. Microbiol. 8, 464.

Erikson, D. \& Porteous, J. W. (1955). Commensalism in pathogenic anaerobic Actinomyces cultures. J. gen. Microbiol. 13, 261.

Frank, H. H. \& Skinner, C. E. (1954). The relationship between Actinomyces bovis and Lactobacillus bifidus. Mycologia, 46, 728.

Friedemann, T. E. (1938). The identification and quantitative determination of volatile alcohols and acids. J. biol. Chem. 123, 161.

Gest, H. (1952). Molecular hydrogen: oxidation and formation in cell free systems. Phosph. Metabolism, 2, 522.

Gyllenserg, H. G. (1955). The development of the 'Straight Rod Type' of Lactobacillus bifidus. J, gen. Microbiol. 13, 394.

György, P., Norris, R. F. \& Rose, C. S. (1954). Bifidus factor. I. A variant of Lactobacillus bifidus requiring a special growth factor. Arch. Biochem. Biophys. 48, 193.

Hayward, A. C., Hale, C. M. F. \& Bisset, K. A. (1955). The morphology and relationships of 'Lactobacillus' bifidus. J. gen. Microbiol. 13, 292.

Hodges, E. A., Coolidge, 'T. B. \& Harrison, R. W. (1951). Further observations on metabolic changes in oral lactobacilli. J. infect. Dis. 88, 237.

Howell, A. \& Pine, L. (1956). Studies on the growth of species of Actinomyces. I. Cultivation in a synthetic medium with starch. J. Bact. 71, 47.

Huhtanen, C. N. (1955). Pantothine and casein hydrolysate in the growth of certain Lactobacilli. Proc. Soc. exp. Biol., N.Y. 88, 311.

Johnson, M. J. (1949). A rapid micromethod for estimation of non-volatile organic matter. J. biol. Chem. 181, 707.

Kennedy, E. P. \& Barker, H. A. (1951). Paper chromatography of volatile acids. Analyt. Chem. 23, 1033.

Ludwig, T. G. \& Sullivan, H. R. (1952). Studies of the flora of the mouth. VIII. An examination of selected human strains of anaerobic actinomyces. Aust. J. exp. Biol. med. Sci. 30, 81.

Manual of Methods for Pure Culture Study of Bacteria (1946). Geneva, N.Y.: Biotech Publications.

Negroni, P. \& Fisciner, I. (1944). Estudio sobre el Lactobacillus bifidus (Tissier) Kulp y Rettger. Rev. Soc. argent. Biol. 20, 313.

Neish, H, C. (1950). Analytical methods for bacterial fermentations. Nat. Res. Coun. Canada, Saskatoon Rep. no. 46-8-3.

Norris, R. F., Flanders, T., Tomarelli, R. M. \& György, P. (1950). The isolation and cultivation of Lactobacillus bifidus: A comparison of branched and unbranched strains. J. Bact. 60, 681.

Orla-Jensen, S. (1943). The lactic acid bacteria. K. danske vidensk. Selsk. 8 ser. 5,81 . 
Pappenheimer, A. M. \& Shaskan, E. (1944). Effect of iron on carbohydrate metabolism of Clostridium relchii. J. biol. Chem. 155, 265.

Pederson, C. S., Peterson, W. H. \& Fred, E. B. (1926). The forms of lactic acid produced by pure and mixed cultures of bacteria. J. biol. Chem. 68, 151.

Peters, J. P. \& VAN Slyke, D. D. (1932). Quantitative Clinical Chemistry. Baltimore: The Williams and Wilkins Co.

Phares, E. F., Mosbach, E. H., Denison, F. W. \& Carson, S. F. (1952). Separation of biosynthetic organic acids by partition chromatography. Analyt. Chem. 24, 660.

Puntoni, V. (1937). Sulle relazioni fra il b. bifido gli attinomiceti anaerobi typo Wolff-Israel. Ann. Igiene (sper.), 47, 157.

Rabinowitz, J. C. \& Barker, H. A. (1956). Purine fermentation by Clostridium cylindrosporum. I. Tracer experiments on the fermentation of guanine. J. biol. Chem. 218, 147.

REDFIELD, R. R. (1953). Two-dimensional paper chromatographic systems with high resolving power of amino acids. Biochim. biophys. Acta, 10, 344.

Rose, C. S., Luchi, R. J., Avery, A., Norris, R. F. \& György, P. (1953). Monoand disaccharides in growth of Lactobacillus bifidus and its mutants. Proc. Soc. exp. Biol., N.Y. 81, 712.

Rosebury, T., Eprs, L. J. \& Clark, A. R. (1944). A study of the isolation, cultivation, and pathogenicity of Actinomyces israeli recovered from the human mouth and from actinomycosis in man. J. infect. Dis. 74, 131.

Smith, G. F. (1950). Analytical Applications of Periodic Acid, Iodic Acid and their Salts. Columbus, U.S.A.: The G. Frederick Smith Chemical Co.

Thompson, L. (1950). Isolation and comparison of Actinomyces from human and bovine infections. Proc. Mayo Clin. 25, 81.

Thompson, L. \& Lovestedt, S. A. (1951). An Actinomyces-like organism obtained from the human mouth. Proc. Mayo Clin. 26, i69.

Umbreit, W. W., Burris, R. H. \& Stauffer, J. F. (1949). Manometric Techniques and Tissue Metabolism. 2nd ed. Minneapons: Burgess Publishing Co.

Veltre, F., Shorb, M. S. \& Pelczar, M. J. (1953). Nutritional requirements of Lactobacillus bifidus isolated from poults and chicks. Proc. Soc. exp. Biol., N.Y. 83, 284.

Vulllemin, P. (1931). Les champignons parasites et les mycoses de l'homme. Paris: Lechevalier.

Waring, W. S. \& Werkman, C. H. (1944). Iron deficiency in bacterial metabolism. Arch. Biochem. 4, 75.

Westerfeld, W. W. (1945). A colorimetric determination of blood acetoin. J. biol. Chem. 161, 495.

WiNNICK, T. H. (1942). Determination of ethyl alcohol by microdiffusion. Industr. Engng Chem. (Anal.), 14, 523.

(Received 26 March 1956) 